\title{
Attention-Deficit Hyperactivity Disorder in the EFL Classroom: A Case Study
}

\section{Olmedo Bula Villalobos}

Profesor de Inglés del Centro de Idiomas de la UNED.

Recibido: 5 de octubre de 2011

RESUMEN

Este estudio de caso reflexiona sobre la experiencia de la puesta en práctica de un plan para un estudiante con trastorno de hiperactividad con déficit de atención que asiste a un colegio en un entorno de ILE en Costa Rica. El plan consistió en un conjunto de cuatro observaciones y cuatro sesiones de trabajo. Además el estudio reporta sobre las estrategias y técnicas usadas con el estudiante y el profesor para mejorar el desempeño del estudiante en el aula. Los resultados y el análisis de este estudio de caso son también abordados. Uno de los principales hallazgos es que este desorden puede ser tratado efectivamente.

\section{PALABRAS CLAVE}

TDAH, estudio de caso, estrategias, técnicas, ILE, falta de atención, hiperactividad, impulsividad

Aceptado: 24 de noviembre de 2011

\section{SUMMARY}

This case study reflects upon the experience of implementing a plan for a student with attention-deficit hyperactivity disorder attending a high school within an EFL environment in Costa Rica. The plan consisted of a set of four observations and four work sessions. In addition, the study reports on the strategies and techniques used with the student and the teacher in order to improve the student's performance in the class. The results and the analysis of the case study are also discussed. One of the main findings is that this disorder can be effectively treated.

\section{KEY WORDS}

ADHD, case study, strategies, techniques, EFL, inattention, hyperactivity, impulsivity

\section{INTRODUCTION}

Attention-Deficit Hyperactivity Disorder, hereafter referred to as ADHD, is one of the most common disorders in the classrooms (Sousa, 2001). Students with ADHD are a real challenge for language instructors and parents. Inattention, hyperactivity, and impulsivity certainly do not fit when it comes to language acquisition as a foreign language. ADHD is certainly a serious condition. This disorder can make life difficult for families, instructors, and classmates basically because of its interference with concentration and mobility in the language classroom. If left untreated or misdiagnosed, ADHD might become an even more complex disorder. Becoming an autonomous learner and a competent speaker are the ultimate goals of language teaching. Students suffering ADHD just want to succeed in a non-threatening environment conducive to effective language acquisition. The teacher: "In general terms, he is a good student. The problem is that he is almost never paying attention to my explanations and guidelines. Sometimes he can't control his hyperactivity. It definitely affects him in the learning-teaching process". The parent: "I do love him... but 
he is so impulsive and even bossy. Sometimes he wants to climb the walls, literally climb the walls. He simply can not sit still". The student: "Well, they keep telling me off and I don't understand why. My dad even yells at me... My English teacher? She is ok, I guess".

This case study reflects upon the experience of implementing a plan for a student with ADHD in an English as a Foreign Language (EFL) environment in Costa Rica. Furthermore, the study reports on the strategies and techniques used with the student and the teacher. The results and the analysis of the case study are also discussed. At this point, it is relevant to mention that because of a privacy request from the parents and to protect the student's identity, a fictitious name was used. The subject of the case study is to be called $\mathrm{Ngäbe}$.

\section{A Review of the Literature: What is ADHD?}

Several definitions of ADHD have been provided by different researchers and authors. Sousa (2001) points out:

Attention-deficit hyperactivity disorder (ADHD) is a syndrome that interferes with and individual's ability to focus (inattention), regulate activity level (hyperactivity), and inhibit behaviour (impulsivity).

It is one of the most common learning disorders in children and adolescents. It affects an estimated 4.1 percent of youths ages 9 to 17 for a period of at least six months. (Sousa, 2001, p. 47) (Sic)

ADHD is also defined as being excessively distracted, and this is usually accompanied by impulsivity and hyperactivity. It is present by the age of seven years old, and it should be apparent in more than one setting, for instance at home and in the classroom (Hanne, 2003). People can be distracted from an idea, an emotion, an action, or a relationship. The distraction may come from outside or be within the person's mind. With the tendency to be distracted, a short-term memory usually comes.
ADHD is a common behavioural disorder that affects an estimated $8 \%$ to $10 \%$ of school-aged children. Boys are about three times more likely than girls to be diagnosed with it, though it is not yet understood why (Sousa, 2001). Children with ADHD act without thinking, are hyperactive, and have trouble focusing. They may understand what is expected from them but have trouble following through because they cannot sit still, pay attention, or attend to details (Douglas, 2005).

Three types of ADHD have been established according to which symptoms are the strongest in the individual (Copeland \& Love, 1992). These can be described as follows: a) predominantly inattentive type: it is hard for the individual to organize or finish a task, to pay attention to details, or to follow instructions or conversations. The person is easily distracted or forgets details of daily routines; b) predominantly hyperactive-impulsive type: the person fidgets and talks a lot. It is hard to sit still for long (for instance when eating a meal or while doing homework). Smaller children may run, jump, or climb constantly. The individual feels restless and has trouble with impulsivity. Someone who is impulsive may interrupt others a lot, grab things from people, or speak at inappropriate times. It is certainly hard for the person to wait for his or her turn or to listen to directions. A person with impulsivity may have more accidents and injuries than others; c) a combined type of the previous behaviours: symptoms of the above two types are equally predominant in the individual.

In regard to the causes of ADHD, Sousa (2001) has stated:

The exact causes of ADHD are unknown. Scientific evidence indicates that this is a neurologically based medical problem for which there may be several causes. Some research studies suggest that the disorder results from an imbalance in certain neurotransmitters (most likely dopamine and serotonin) that help the brain regulate focus and behavior...

$A D H D$ has been associated with symptoms in children after difficult pregnancies and problem 
deliveries. Maternal smoking as well as exposure to environmental toxins, such as dioxins, during pregnancy also increase the risk of an ADHD child.

(Sousa, 2001, pp. 48-49)

Although the exact cause of ADHD remains unknown, research has increased in the last decades. ADHD is a complex problem, indeed. No one really knows what causes ADHD. It is generally agreed by the medical and scientific community that ADHD is biological in nature (Coghill, 2004). Many believe that it results from a chemical imbalance in the brain (Coghill, 2004). The possibility of a genetic cause of ADHD is further supported by the fact that ADHD appears to run in families. Between 10\% and $35 \%$ of children with ADHD, have a firstdegree relative with past or present ADHD history. Approximately half of parents, who have been diagnosed with ADHD themselves, will have a child with this learning disorder (Ambrosini \& Rapport, 1999). ADHD is not usually caused by excessive television watching, excessive video-game playing, sugar, caffeine, food colourings, poor home life, poor schooling, diets, hormones, or poor parenting (Lilly, 2003).

Scientific studies have shown that people with ADHD can have abnormalities in some parts of the brain, including the prefrontal cortex. The prefrontal cortex is the area of the brain that controls executive functions. Executive functions are specific mental activities that allow self-control. The core symptoms of ADHD - hyperactivity, impulsivity, and inattention - may all rise due to problems with executive functions. Studies have also shown that people with ADHD can have different levels of certain neurotransmitters, such as dopamine and noradrenaline. Both of these neurotransmitters are involved in executive functions (Coghill, 2004). Current thinking suggests that an imbalance of some of the neurotransmitter chemicals in the brain is important in ADHD (Coghill, 2004).

In regard to consequences on learning a foreign language, this combination in children (distraction and poor, short-term memory) can cause learning difficulties and underachieve- ment compared with the child's actual ability (Hanne, 2003). Sometimes this includes dyslexia, even to the point of illiteracy. In adults, distraction will cause forgetfulness of names, phone numbers, appointments, car keys, cell phones, and wallets. Moreover, poor organization is stressful for everyone involved in the learning process, and stress often leads to conflict and depression in the classroom. One of the difficulties in diagnosing ADHD is that it is often found in conjunction with other problems (Douglas, 2005). These are called coexisting conditions, and about two thirds of all students with ADHD have one. At least $35 \%$ of all children with ADHD also have oppositional defiant disorder, which is characterized by stubbornness, outbursts of temper, and acts of defiance and rule breaking (Douglas, 2005).

Conduct disorders are similar but feature more severe hostility and aggression. Children who have conduct disorders are more likely to get into trouble with authority figures and, later, with the law. Oppositional defiant disorder and conduct disorder are seen most commonly with the hyperactive and combined subtypes of ADHD. About half of all students with ADHD also have a specific learning disability. One of the most common problems is dyslexia. Here it is significant to state that ADHD is not a learning disability. Finally, ADHD's interference with concentration and attention can make it even more difficult for a student to perform well in the educational system (Douglas, 2005). These are significant considerations of the ADHD concept.

\section{METHODOLOGY}

This case study is an example of qualitative descriptive research. It is qualitative descriptive research because the case study is used to look at, describe, interpret, and analyse an individual and his condition in a detailed way in order to seek a holistic, in-depth understanding of the situation. Yin (1984) defines the case 
study research method as an "empirical inquiry that investigates a contemporary phenomenon within its real-life context; when the boundaries between phenomenon and context are not clearly evident; and in which multiple sources of evidence are used" (Yin, 1984, p. 23). Likewise, it is true that case studies examine the interplay of all variables to provide a thorough understanding of a specific situation.

\section{- Student's Background}

A general overview of the student's background will be offered in this section. Ngäbe is a fourteen year-old, male, Caucasian student. His native language is Spanish. According to his academic file, Ngäbe was diagnosed as having ADHD because of the following symptoms: has difficulty playing quietly during the breaks, often shifts from one uncompleted activity to another, is easily distracted by stimuli, has difficulty remaining seated when required to do so, has difficulty following instructions from others, talks excessively, interrupts or intrudes on others, does not seem to listen to what is being said or explained, is very impulsive and disoriented, does not plan anything, and fails to handle daily responsibilities that require restraint and a sense of timing. Even though Ngäbe was already diagnosed as having ADHD, the English teacher and the researcher decided to use an instrument to gather more information about his current condition in order to affect in a positive and effective way the learningteaching process. Refer to Table 1 to go over this information.

Ngäbe is an eighth grader currently attending a high school in the San José area. Ngäbe was diagnosed as having ADHD when he was in fifth grade of elementary school. Ngäbe seems to have an important support from parents and other family members. Basically, his mother checks on his school work on a daily basis.

Next, a series of four observations were done in order for Ngäbe to get familiar with the researcher and for the researcher to have a general understanding of the class environment and Ngäbe's behaviour. Based on the observations, the assessment of the instrument, and the detailed analysis of the academic file, one can tell that Ngäbe is an intelligent student, indeed. He is just clumsy, has difficulties following instructions, talks excessively interrupting others, and almost never pays attention to what is being explained. Moreover, Ngäbe has a predominantly hyperactive-impulsive type of ADHD. In addition, the vast majority of Ngäbe's previous teachers have described his school performance as "poor", "clever and talkative", "messy", "highly-dependant on others to finish class work and assigned tasks", "smart but distractive", "not interested in the topic", "moody", "nerve-wracking and unique". In addition, one might say that $\mathrm{Ngäbe}$ is a student with right-brain dominance. Ngäbe is definitely an intuitive, spontaneous, creative, diffusive, and visually-oriented student. Ngäbe's general average grades in previous years were 65 's, just enough to promote and go to the upper level. Additionally, he said he enjoys his English lessons, but it is really difficult for him to acquire new vocabulary. This year $\mathrm{Ngäbe}$ is getting low grades, a 58 during the first period, which is not a passing grade.

Furthermore, Ngäbe's most common behaviours in the English class include: standing up with no real purpose, having problems interacting quietly, having a messy backpack and desk, easily distracting himself, poor planning skills, constantly interrupting students and the teacher, moving from chair to chair, not finishing tasks on time, talking aloud, not focusing on teacher's instructions, having an occasionally attention-getting behaviour, and sometimes showing a small degree of fidgeting. At this point, it is relevant to mention that before getting engaged in this project, Ngäbe's parents gave their consent to the implementation plan. Moreover, they fully supported the researcher and the English teacher when implementing the different strategies and techniques. 
Table 1. Indicators of ADHD.

\begin{tabular}{|l|l|l|}
\hline \multicolumn{1}{|c|}{ Behaviour } & Yes & No \\
\hline Interrupts or intrudes the teacher and other students. & & \\
\hline Blurts out answers and opinions. & & \\
\hline Has difficulty waiting for his turn. & & \\
\hline Constantly stands up for no apparent reason. & & \\
\hline Is very talkative. & & \\
\hline Might dash around or climb. & & \\
\hline Fidgets excessively with hands or feet. & & \\
\hline Is easily distracted by extraneous stimuli. & & \\
\hline Is very forgetful. & & \\
\hline Cannot sit still for short periods of time. & & \\
\hline Does not pay attention to details. & & \\
\hline Shows difficulty sustaining attention. & & \\
\hline Does not finish on time the assigned tasks. & & \\
\hline Loses personal belongings. & & \\
\hline Rarely finishes tasks and assignments. & & \\
\hline Impulsively calls out answers. & & \\
\hline Has a short-term memory. & & \\
\hline Has a messy desk. & & \\
\hline
\end{tabular}

Finally, the following are the current accommodations the English teacher is implementing with Ngäbe: the student will have twenty extra minutes when doing the exams; the student will be seated in the first row; the teacher will constantly check student's work and notebook; and the student will have a tutor (buddy system) in the class to remind him of class work and assignments. These are some significant considerations of the student's background.

\section{Intervention Plan}

A general description of the intervention plan will be offered in this section. This intervention plan was specifically designed for a student with ADHD. The plan intended to make a posi- tive influence in Ngäbe's disorder to improve his general performance in the EFL classroom. It also intended to understand the generalities of a qualitative descriptive case study of a student with ADHD. The plan contains a set of strategies and activities to be developed with both, the English teacher and the student with ADHD. The plan consisted of four observations of the English lesson in order for the researcher to have a general overview of the class environment and Ngäbe's behaviour and for Ngäbe to get familiar with the researcher and the procedures to be followed. These observations were done in an unobtrusive way in order not to alter the normal pace of the class. In addition, the plan also included a set of four work sessions during the English class in which the English teacher, the researcher, and Ngäbe worked on and went over the different strategies designed 
for this intervention plan. These sessions were held every other week in order for Ngäbe to digest the information and apply the different strategies in the English lessons. Predicting is also an important part of this intervention plan. It was expected that Ngäbe would improve his condition and his general performance in the EFL classroom.

\section{Specific Objectives}

1. Develop a set of strategies and techniques for a student with ADHD and for a teacher working with a student with ADHD in an EFL environment.

2. Develop a sense of responsibility and quality work in a student with ADHD in the EFL classroom.

\section{RESULTS}

\section{Description of Strategies and Activities}

The following is a description of the activities and the strategies implemented with the subject of the study during the four sessions of work.

\section{First session}

The researcher and $\mathrm{Ngäbe}$ gathered together around fifteen minutes before the beginning of the class in order to decide on a specific color and a picture for the English notebook and book. The researcher strongly suggested a picture or theme related to cars and engines, basically because $\mathrm{Ngäbe}$ clearly demonstrates interest and a lot of knowledge on the topic. The researcher and Ngäbe discussed the importance of bringing the different materials for the English lesson. Next, the researcher and Ngäbe agreed on using a highlighter at all times during the English lessons in order to highlight whatever seemed relevant to the student. The researcher demonstrated the technique himself. Next, Ngäbe practiced the strategy in the class. Basically, Ngäbe highlighted important relatives and family members. He also highlighted people's physical descriptions and personality traits. The researcher also explained the importance of using a pocket calendar not only to keep important information in mind, but to accomplish duties and tasks when required. Ngäbe agreed on using a small, easy-to-carry pocket calendar to write all tasks and assignments, and to check it on a daily basis at the same time after school. The researcher showed Ngäbe his own calendar and demonstrated how to jot down relevant information using keywords and reminders. Moreover, the researcher provided the student with a daily behavioral chart so the student could write and reflect on his positive and negative behaviors and progress in the English class. This instrument consisted of fifteen positive and negative behaviors. In order to foster confidence, this instrument was completed in Ngäbe's first language. The researcher and Ngäbe filled out one chart as an example, so the student felt comfortable expressing his behaviors and attitudes on a daily basis. The English teacher, the researcher, Ngäbe's parents, and Ngäbe reviewed these charts on a weekly basis in order to provide feedback and analyze the information.

\section{Second session}

The researcher explained to Ngäbe the importance of recording the English lesson with an audio device. Basically the researcher highlighted the importance of going back as many times as necessary in order to check and reinforce the material studied in class and to clarify any doubts. The researcher brought his own recording device in order to record the English lesson. At the end of the lesson, the researcher and Ngäbe went over the recording to check and analyze the technique and its subtleties. The stakeholders agreed on two micro breaks of no more than two minutes for each lesson of 
forty minutes. The student was not allowed to share this information with the rest of his classmates. The researcher explained to Ngäbe the concept of controlled physical movement in the class in order to let the student wiggle and reactivate his focus and attention span on the task. The student was allowed to use a fidget object: a mini ball made of cloth. Ngäbe did not have authorization to throw or bounce the ball. The researcher also explained to Ngäbe that the idea of using the ball was to let him concentrate as his hands were busy with something else. The researcher provided the student with a mini ball for that English lesson so that the student could feel the sensation of using the ball and unconsciously experience the strategy.

\section{Third session}

The student was assigned a physical job within the class. In other words, Ngäbe was going to be in charge of erasing the whiteboard from that moment on. In addition, he had the responsibility of distributing and collecting the copies, assignments, and projects. The researcher explained to Ngäbe that the underlying idea of these duties was to let him move around the classroom in a controlled environment. Next, a pre-arranged signal was established in order to let Ngäbe know that he was losing concentration or that he was moving excessively. This specific signal was used to make the student aware of the need to slow down and stop his negative behavior or attitudes. Several signals were practiced in order to decide which of these made the student feel more comfortable. The final decision was made on a signal where the teacher touched his left ear to make Ngäbe notice that his behavior had to change. Furthermore, the researcher constructed a set of post checklists for specific tasks and assignments that were done in the classroom. The researcher explained to Ngäbe that these lists consisted of organizational skills to improve his general performance in the classroom. The student and the researcher completed a list in order to understand the procedures. Ngäbe was encouraged to use the list as an effective tool for
EFL acquisition. The researcher consulted the English teacher beforehand in order to manage and handle the objectives, activities, and procedures to construct the checklists. As previously stated, this instrument was completed in Ngäbe's native language to foster confidence.

\section{Fourth session}

A specific folder was chosen in order to keep all the materials, copies, and assignments for the English subject. This folder included a section for parents-English teacher communication in which they included details, comments, thoughts, ideas, suggestions, and positive or negative feedback. Then when it came to reading, Ngäbe used a pencil across the page, so he could stay focused and keep his pace.

This was a general description of the activities and techniques used with $\mathrm{Ngäbe}$ in order to improve his academic performance.

\section{- Analysis}

In the following section, an analysis of the implementation plan will be presented. Ngäbe seemed to be very excited about the progress and implementation of the plan. During the first session, $\mathrm{Ngäbe}$ was very cooperative and demonstrated genuine interest in the strategies and techniques as well. Ngäbe decided to put a colorful picture of a Ferrari Fiorano 599 for his English notebook and a Ferrari Italia 458 for his English book. The student pointed out that he does not forget his material anymore, but the English teacher also said that Ngäbe sometimes spends a considerable amount of time chatting with other classmates about the pictures and cars in general though. It is interesting to notice how a simple picture can generate so many insights. The fact that due to the picture the student is now bringing his material to the English class is a significant one. Ngäbe said the highlighter was definitely a plus. $\mathrm{He}$ used the marker at all times to underline and 
highlight relevant information. Moreover, he wrote comments and notes on the book and the notebook to clarify doubts and have a better understanding of the topic studied in class, which one can consider a superb strategy the student discovered on his own. Additionally, Ngäbe said he uses the highlighter in order to stay focused when reading.

Next, Ngäbe also mentioned that he used the highlighter as a fidget object to keep his hands busy. The English teacher pointed out that Ngäbe's concentration and attention span seem to be improving, but the student often tapped the highlighter on the desk interrupting the flow of the class. Now Ngäbe has an easy-to-carry pocket calendar and it was working properly basically because he wrote and checked the different assignments. He said that getting used to writing in the calendar on a daily basis was somehow difficult for him because he wrote a lot of information there but did not check it. He recognized that sometimes he simply forgot to do it. The student mentioned that he and his mother checked the calendar every other day around 6:00 p.m. He was also using the calendar to write information about other subjects. One has to recognize that a routine like this one requires a lot of effort, time, and consistency to be established and internalized. Personally the researcher believes Ngäbe is on the right track and he has started to working with the calendar as an effective organizational tool. Then the English teacher commented that Ngäbe shows an important degree of maturity and responsibility when completing the behavioral charts and the post checklists. Next, the student has not been able to get a recording device. The researcher strongly believes that getting the recording device is paramount for overcoming Ngäbe's learning disorder basically because this will give him plenty of opportunities to recheck the content of the class. Going back to the material as many times as necessary becomes relevant to improve his academic skills. Next, Ngäbe manifested that the micro breaks were truly working because he was focusing on what was required from him. The English teacher mentioned that Ngäbe was definitely more concentrated during longer periods of time, up to 15 minutes. In addition, the English teacher stated that she was using the physical jobs, not only with Ngäbe but with other students as well. When a student started interrupting, this student was sent to run an errand to the secretary's office in a very subtle way.

Later, when interviewing the English teacher about the outcome of the strategies and techniques, she stated that these activities were "very thought-provoking" and "extremely useful". The English teacher also mentioned that these activities required a lot of planning and extra time though. She also mentioned she was getting more organized, not only for Ngäbe's case, but her planning skills were definitely improving. The English teacher was paying more attention to structure and routine (writing instructions on the board, providing classroom arrangement for specific purposes and activities, using body gestures, having visual contact, explanation of negative and positive behavior consequence, and using more TPR activities) within the classroom. Moreover, the English teacher is now using encouragement, positive feedback, and motivation with her students with learning disorders. The importance of having no more than two students with accommodations in order to attend their specific needs to overcome their learning disorders was discussed.

During the last session, the researcher, the English teacher, and Ngäbe analyzed the behavioral charts, the post checklists, and his general attitude and behavior towards the intervention plan and his performance as well. In general terms, Ngäbe was indeed improving his performance because of his personal awareness and effort. The English teacher truly believed the techniques and the strategies were causing a positive impact in Ngäbe's general attitude towards the class. The student definitely understood, not only he must get a 72 in order to promote to the next level but a solid basis for the $11^{\text {th }}$ grade national exams. Later, Ngäbe 
and the English teacher pointed out that the most useful strategies were the checklists basically because they provided organizational skills and time limits for the different tasks. The student said that he knew specifically what was required to do.

Due to Ngäbe's busy schedule, the researcher was not able to raise phonological awareness by teaching phonemes in the student's L1 and the sound system of the target language explicitly. The researcher strongly believes this might have helped the student with the actual perception, production, and acquisition of the foreign language (linguistic codes). Finally, one can certainly say that $\mathrm{Ngäbe}$ responded properly to the implementation plan, modifying negative behaviors and attitudes and becoming an effective English learner. In general terms, Ngäbe definitely improved his condition and his general performance in the EFL classroom. The following statements from the different stakeholders seem to confirm it:

"He is definitely paying attention to my explanations and guidelines. That fact that he can concentrate and focus for more than 10 minutes is really beneficial."

"Well, now, he brings his material to class. Believe or not, this is a major breakthrough for him."

"He is not that impulsive now. He tries to control himself. I can see that."

"The signal is a plus, a very easy and practical way for me to let him know things are getting out of control."

\footnotetext{
"Now with the checklists, I know what is expected from me. I understand what I have to do."

"I do believe I'm paying more attention now, which is good."
}

Finally, the following table contains a list of strategies and techniques for teachers working with ADHD students in the EFL classroom. The aim of this list is to manage students with ADHD more effectively. The researcher and the English teacher agreed that by using and implementing this list, results will be more productive in behavioral and academic terms (Ambrosini \& Rapport, 1999; Coghill, 2004i Copeland \& Love, 1992; Douglas, 2005; Hanne, 2003; Lilly, 2003; Sousa, 2001).

\section{CONCLUSION}

Some conclusions are discussed in this part. These can be summarized as follows.

Even though ADHD represents a complex challenge to language instructors, the disorder itself can be effectively treated. Next, the attitude and knowledge exhibited by both, the student and the English teacher were determinant to the success of the implementation plan. Attitude and knowledge are equally significant, indeed.

This case study was a revealing one in terms of the researcher's own teaching style and how these techniques and strategies can actually help students suffering ADHD overcome specific problems.

Since it affects an important amount of students, ADHD must be taken seriously. ADHD truly affects students when immerse in the process of acquiring a foreign language. Accommodations and adjustments become a must from the different stakeholders. Opportunities for students with ADHD to develop their full potential must not be neglected.

It is also true that $\mathrm{Ngäbe}$ has become a more autonomous and independent learner, taking more responsibilities in his learning process. The researcher strongly believes that $\mathrm{Ngäbe}$ has given an important step in terms of accountability. Students with ADHD are just as intelligent, clever, misbehaved, funny, unique, and amazing as the rest of the students. They do strive and they just want to succeed. Teachers, parents, and society must provide a safe environment conducive to effective language acquisition. 
Table 2. List of Strategies and Techniques for Teachers working with ADHD Students

\begin{tabular}{|c|c|}
\hline $\begin{array}{l}\text { When possible, raise phonological awareness by } \\
\text { teaching phonemes in students' L1. }\end{array}$ & $\begin{array}{l}\text { Make sure you teach the sound system of the tar- } \\
\text { get language explicitly. }\end{array}$ \\
\hline Sit students in a place with little distraction. & Make frequent visual contact. \\
\hline Give short and clear instructions several times. & Have students repeat instructions. \\
\hline Post checklists for the different tasks. & Have rewards for in-school work and homework. \\
\hline $\begin{array}{l}\text { Write the objectives and instructions on the } \\
\text { board. }\end{array}$ & Make students use a highlighter. \\
\hline Encourage the use of pocket calendars. & Use physical proximity and touch. \\
\hline $\begin{array}{l}\text { Signal that someone is to answer a question } \\
\text { about what is being said. }\end{array}$ & $\begin{array}{l}\text { Ask a simple question to a child whose attention } \\
\text { is beginning to wander (not even related to the } \\
\text { topic). }\end{array}$ \\
\hline State behaviour that you want and expect. & $\begin{array}{l}\text { Use students' names in the material being cov- } \\
\text { ered. }\end{array}$ \\
\hline $\begin{array}{l}\text { Share with students your expectations of what } \\
\text { paying attention looks like. }\end{array}$ & $\begin{array}{l}\text { Teach learning strategies (predicting and recipro- } \\
\text { cation). }\end{array}$ \\
\hline Try desperately not to criticize students. & Write negative and positive behaviour. \\
\hline Use the buddy system. & Handle medication with sensitivity. \\
\hline Develop a sense of humor. & Emphasize quality of work - not quantity. \\
\hline Remove distracting items from the classroom. & Increase the distance between desks. \\
\hline Vary voice, tone, and inflection. & Move around the classroom. \\
\hline Use body gestures. & Periodically record or videotape your lessons. \\
\hline Alternate physical and mental activities. & Believe in positive rather than negative. \\
\hline $\begin{array}{l}\text { Encourage planning by frequently using lists, } \\
\text { charts, and calendars. }\end{array}$ & $\begin{array}{l}\text { Use the wall clock. Tell students how long they are } \\
\text { to work on assignments. }\end{array}$ \\
\hline Communicate the value of accuracy over speed. & Use attention getters before explaining. \\
\hline $\begin{array}{l}\text { Increase frequency and content of positive rein- } \\
\text { forcement. }\end{array}$ & $\begin{array}{l}\text { Use and promote contracts with students and par- } \\
\text { ents. }\end{array}$ \\
\hline $\begin{array}{l}\text { Give students a physical responsibility in the } \\
\text { class. }\end{array}$ & Prearrange signals with students. \\
\hline Expect students to wiggle. & Use a folder for copies and homework. \\
\hline $\begin{array}{l}\text { When reading, allow students to use a pen across } \\
\text { the page. }\end{array}$ & $\begin{array}{l}\text { Consider having students complete every third } \\
\text { question or item, instead of answering each one. }\end{array}$ \\
\hline Expect the unexpected. & Use mnemonics to help retention and memory. \\
\hline Do a countdown for the last minutes of activities. & Avoid more than 20 minutes of seatwork. \\
\hline Incorporate more TPR activities. & Increase the novelty of lesson by considering MIs. \\
\hline Knowledge and attitude are equally important. & $\begin{array}{l}\text { Provide a positive and non-threatening environ- } \\
\text { ment. }\end{array}$ \\
\hline Establish a daily routine. & Promote hands-on activities whenever possible. \\
\hline
\end{tabular}


In addition, more research specifically addressed to language acquisition in an EFL environment is required due to the impact of ADHD on demographics. Because of the narrow scope of this study, many questions have not been answered regarding ADHD in the EFL classroom: What is the connection between raising phonological awareness and EFL acquisition? How does ADHD affect EFL acquisition at early stages? How are the universities preparing language students teachers to cope with ADHD and other disorders in general? What would have been the implications of a national intervention plan for ADHD students in an EFL environment?

Understanding the subtleties of ADHD is crucial for language instructors working with students who have this disorder. When teachers do not provide scaffolding to acquire a foreign language, being in class is like being amid another completely different culture of the own.

Finally, one can certainly say that the implementation plan made a positive influence in Ngäbe's disorder and it improved his general performance in the EFL classroom.

Correspondence concerning this article should be addressed to Olmedo Bula Villalobos, Language Center, Universidad Estatal a Distancia, Mercedes, Montes de Oca San José, Costa Rica, Central America, 474-2050 San Pedro. E-mail: obula@uned.ac.cr

\section{REFERENCES}

Ambrosini, E., \& Rapport, J. (1999). Treatment of ADHD. Retrieved March 25, 2011, from http:// www.adhd.org.nz/cause1/article345.html

Coghill, D. (2004). What causes ADHD? Retrieved March 25, 2011, from http://premium.netdoktor/uk/adhd/childhood/behaviour/aerticle. jsp?articleldent=uk.adhd. childhood. behaviour. uk_adhd_xmlarticle_0045322

Copeland, E., \& Love, V. (1992). Attention without tension. Atlanta: Childhood, Inc.
Doughty, C., \& Varela, E. (1998). Communicative Focus on Form. In C. Doughty \& J. Williams (Ed.), Focus on form in classroom second language acquisition (pp. 114-138). Cambridge: Cambridge University Press.

Douglas, W. (2005). ADHD description. Retrieved March 25, 2011, from http://www.kidshealth.org/ parent/medical/learning/behavior/adhd.html

Freeman, I. (2008). Diverse learners in the mainstream classroom. New York: Heinemann.

Gass, S., \& Selinker, L. (2001). Second language acquisition: An introductory course. Mahwah, New Jersey: Lawrence Erlbaum Associates.

Hanne, T. (2003). What is ADHD? Retrieved March 25, 2011, from http://www.everybody.co.nz/page12dcbg5eo-elb2-86cd-dag07342e7b8.aspx

Jensen, E. (2000). Different brains, different learners. San Diego: The Brain Store.

Leeman, J. (2003). Feedback in L2 learning: responding to errors during practice. In R. DeKeyser (Ed.), Practicing in a second language: perspectives from applied linguistics and cognitive psychology (pp. 37-63). Cambridge University Press.

Lilly, E. (2003). Causes of ADHD. Retrieved March 25, 2011, from http://www.mental-healthmatters.com/articles/article.php?artID $=1744$

Méndez, J. (2008). Áreas de corrección para niños con problemas de aprendizaje y su control. San José: EUNED.

Nunan, D., \& Lamb, C. (1996). The self-directed teacher. Cambridge: Cambridge University Press.

Richards, J., \& Rodgers, T. (2001). Approaches and methods in language teaching ( $2^{\text {nd }}$ ed.). NY: Cambridge University Press.

Sousa, D. (2001). How the special needs brain learns. California: Corwin Press.

Yin, R. (1984). Case study research: design and methods. Newbury Park, CA: Sage. 